\title{
Identification through Technical Analysis: A Study of Charting and UK Non-professional Investors
}

\author{
Philip Roscoe and Carole Howorth \\ Lancaster University Management School
}

Re-submitted to Accounting Organizations and Society, February 2008.

Correspondence to: Carole Howorth, Institute for Entrepreneurship and Enterprise Development, Lancaster University Management School, Lancaster, LA1 4YX. Telephone +44 1524594847 Email c.howorth@lancaster.ac.uk

Philip Roscoe, IEED, Lancaster University Management School, Lancaster, LA1 4YX.

Telephone +44 7769737934 Email p.roscoe1@lancs.ac.uk 


\title{
Identification through Technical Analysis: A Study of Charting and UK Non-professional Investors
}

\begin{abstract}
The usefulness of technical analysis, or charting, has been questioned because it flies in the face of the 'random walk' and tests present conflicting results. We examine chartists' decision making techniques and derive a taxonomy of charting strategies based on investors' market ontologies and calculative strategies. This distinguishes between trendseekers and pattern-seekers, and trading as a system or an art. We argue that interpretative activity plays a more important role than previously thought and suggest that charting's main appeal for users lies in its power as a heuristic device regardless of its effectiveness at generating returns.
\end{abstract}

Key words: social studies of finance, charting, heuristic, technical analysis, Fibonnacci, Elliott, individual investors. 
Introduction

Only days after landing in my new job I've found myself praising such statements from investors as: 'I was looking at the ten-day moving average last night and it is a perfect reverse duck tail and pheasant. Let's bet the ranch.' At this juncture my role was only to shout encouragement: 'Yeah! Let's do it.' (Lewis, 1989:192)

In his entertaining account of life as a Salomon Brothers bond salesman, Michael Lewis finds himself bewildered by the investment practice of technical analysis, commonly known as 'charting'. This is a method of identifying investment opportunities using graphs. Unlike fundamental analysis, charting requires no information other than price history; it is not necessary to know the activity - nor even the name - of the company whose shares are traded; nor the precise nature of the financial instrument in question; nor the uses and likely demand for a given commodity. Chartists are not necessarily schooled in the staples of fundamental analysis: economics, accounting, industry expertise and financial modelling. Instead, they use methods of varying complexity to extrapolate past price movements into future predictions. Many researchers share Lewis' bewilderment when encountering charting; for finance researchers especially it flies in the face of the 'random walk' of stock movements and the theory of efficient markets (Malkiel, 2003). Moreover, it ignores the commonsense understanding that security prices should reflect the value of the underlying asset (Preda, in press). 
Despite this there is considerable evidence, offered mainly by finance researchers but also by sociologists, that charting is a popular strategy, even among professional traders (Menkhoff, 1997; Taylor and Allen, 1992; Zaloom, 2003). The employment of its own language, as highlighted in the opening quote, separates charting from other types of analysis, providing status and legitimacy and identifying proponents as experts (Batchelor and Ramyar, 2006; Lo, Mamaysky et al., 2000). However, although there are numerous textbook summaries of charting methods (Batchelor and Raymar 2006), there is a striking absence of evidence on the way that charting is used 'in the wild', and thus little discussion of the calculative strategies and behaviour of individual chartists. This study proposes a conceptualisation of chartists through an inductive examination of how investors who use charting make investment decisions, the techniques that they use, and the way in which they make sense of the markets.

We focus on non-professional (non-salaried) investors for several reasons. They are relatively under researched. They are free from the hierarchical controls that affect professional traders and from the networks built up between them, proximate or otherwise (Buenza and Stark, 2004; Knorr Cetina and Bruegger, 2002; Knorr Cetina and Bruegger, 2000; Zaloom, 2006), because they are investing their own funds and often from their own homes. The result is that the observed decision-making process is less encumbered by exogenous factors. Moreover, recent studies have questioned the behaviour of non-professional (individual) investors, arguing that they are less sophisticated in comparison to professionals and that they process information differently 
(Allee, Battacharya et al., 2007; Frederickson and Miller, 2004). It is suggested that, where individual investors are less-informed, they will be over-confident in their knowledge and trade too aggressively (Bloomfield, Libby et al., 1999). Following Mayall (2006) we define non-professional investors as individuals investing their own money in the stocks of companies through the financial markets; while some may depend on this for their livelihood, the force of 'non-professional' is to distinguish between these and those salaried investors employed by financial organisations.

This article contributes to the growing Social Studies of Finance (SSF) research paradigm. It presents empirical evidence on the activities of non-professional investors that provides a valuable insight into their behaviour. A taxonomy is presented that identifies four types of charting strategy based on the market ontology of individual investors and their calculative autonomy. The taxonomy highlights a differing understanding of how the market is structured (ordered or otherwise) among individuals and different levels of reliance on the calculative activities of other market agents. In each category, the importance of individual interpretative activity and the variations in employment of methods is stressed. The implication for researchers here is twofold: some isolated tests of the efficacy of specific charting methods may lack validity in the real world, and also a concentration on the ability of charting methods to develop excess profits neglects the importance of these methods as heuristic devices located within the broader interpretative skills of their users. We do not claim that our findings, based on a 
limited group of interviewees, are representative of the universe of investors as a whole, but suggest a number of exploratory propositions that can be tested in future research.

\section{Article structure}

In the following section we examine previous studies of technical analysis. These show that charting is widespread, but offer mixed evidence of its success at providing excess profits. We introduce the SSF research project and explain how this literature provides an avenue for better understanding of the calculative activities of chartists. This is followed by an explanation of the research method adopted and an interpretive analysis of interviews detailing the activities of 12 non-professional investors in the UK who use charting tools regularly. The post-analysis conceptualisation derives a four way taxonomy of investors based on their calculative methods and market ontology. The discussion then examines the most important aspects of this conceptualisation, and suggests a number of propositions for future research. The conclusion highlights that this study has important implications for earlier and future research, as well as for practitioners.

\section{Previous Studies}

Two streams of research have considered charting. Researchers in finance have concentrated on showing the popularity of the method and testing its usefulness as a 
method of investment selection, while SSF research has focused on documenting charting as a socially situated practice. This section explains how these two streams of research are drawn upon to guide our study.

\section{Finance research on charting}

Charting has attracted an increasing amount of attention from finance researchers, exhaustively reviewed by Park and Irwin (2004). As well as surveys showing the popularity of charting, there are theoretical explanations based on rational feedback models (De Long, Shleifer et al., 1990; Shliefer and Summers, 1990), noisy rational expectation models and others. The majority of studies, though, focus on the possibility of achieving excess returns using charting methods. This is an important area of research because demonstrations of this directly contradict the Efficient Markets Hypothesis $(\mathrm{EMH})$ assumption that prices contain all known information and that abnormal returns cannot be made either by fundamental or technical analysis (Fama, 1991; 1970; Malkiel, 2003). Tests of EMH consistently present conflicting results (see Zuckerman, (2004) and Preda, (2007) for an explanation based on structural incoherence). Park and Irwin (2004) show that of 92 studies carried out from 1988-2004, 58 report that charting methods consistently generated economic profits, but Park and Irwin suggest that these studies remain methodologically flawed. Their review highlights that there is, as yet, insufficient evidence to determine the efficacy of charting methods one way or the other. 
Despite the existence of positive studies, many finance researchers remain unconvinced of the principles underpinning charting, with critics equating it with 'voodoo finance' and 'alchemy' (Malkiel, 1996). Jegadeesh (2000) suggests that there is 'no plausible explanation as to why these patterns should indeed be expected to repeat.' Batchelor and Ramyar (2006) found no evidence of the existence of Fibonacci series and Elliott wave patterns in the Dow Jones Industrial Average between 1915 and 2003. Malkiel (2003:78) states: 'the record of professionals does not suggest that sufficient predictability exists in the stock market... to produce excess returns', commenting also that with enough time and patience it is possible to tease any pattern out of a given data set. Researchers also complain that testing is difficult because chartists fail to report their results in a rigorous manner, and because rules are so vague and complicated as to make replication impossible (Batchelor and Ramyar, 2006:2).

Within finance, a growing literature also exists on individual investors, where their sub optimal behaviour is compared with the norms of professional finance practice. Examples of this include de Bondt's (1998) survey of individual investor beliefs, and evidence that individual investors tend to place more belief in pro-forma disclosures (Allee et al., 2007), trade too often (Barber and Odean, 2001; 2000), retain losers and sell winners (Odean, 1998b), and buy stocks that have a higher profile in the news (Barber and Odean, 2004). The focus of this article is on the techniques used by chartists in general; while we are looking specifically at non-professional investors there is no data to suggest that 
the techniques used by non-professional investors differ substantially from their professional counterparts.

\section{The social studies of finance (SSF) programme}

Many of the tests of charting in the finance literature are based on assumptions of rational economic behaviour. Social studies of finance have sought to show that the decisions of market actors are influenced by social surroundings, hierarchies and networks. For example, Baker's (1984) study of a trading floor showed that trading pits with smaller crowds could achieve more stable prices than those with larger numbers, although it is possible that these small crowds operated as cartels. Abolafia (1998) argues that market norms, such as transparency, arise out of repeated interactions between traders, rather than existing as a given. Knorr Cetina and Bruegger (2000) and Zaloom (2006) show that traders are constrained by their position in hierarchical organisations, while MacKenzie (2003) shows that the relationships of hedge fund managers located as a social elite in geographic proximity to each other effectively limited their capacity to act as market arbitrageurs.

Sociological work has also focused on the mechanisms of the investment decision. Knorr Cetina and Bruegger's work has centred on the screen as a productive mechanism of the market (Knorr Cetina, 2005; Knorr Cetina and Bruegger, 2002; Knorr Cetina and Bruegger, 2000) while Buenza and Stark (2004) have shown how a trading room 
functions as a calculative device. Michel Callon's theoretical contributions have begun to examine how investment theory and technique may have a substantive role in determining security prices (Callon, 1998; 2007; Callon and Muniesa, 2003); some empirical evidence of this has been produced regarding the implementation of options pricing theory (MacKenzie, 2003; MacKenzie and Millo, 2003) and the technique of portfolio insurance which helped precipitate the 1987 financial market crash (MacKenzie, 2004). Callon (2007) suggests that evidence on charting may further contribute to this topic.

The engagement of social studies of finance with charting has been limited. Preda (in press) has written about the origins of the practice, giving an account of how charting developed beyond a simple technique to an epistemic community represented by 'simultaneously a theory of financial markets, a theory based technique for forecasting prices, a set of instruments, a commodity sold by the members of the group, a commodity around which data processing firms emerged, a media discourse, and a narrative'. Zaloom (2003) encountered the technique in London's trading rooms, noting that decisions cluster around significant numbers, conferring on them an agential property. Godechot (2001) shows that charting is popular among professional traders in Paris. Mayall (2006) makes an important first step in broadening our understanding of individual chartists with her empirical study of non-professional traders in Australia. She identified four 'ideal types' of trading: as a 'scientific' system; as an art based on judgement and intuition; as a game of skill; and as a voyage of exploration. The first, 
'trading as a system', is a category comprising those who strive to remove all human judgment from their trading activity by delegating all the work to a computerised system, while the second, 'trading as an art', comprises those who renounce algorithm-based selection entirely in favour of cognitive, often visual, judgement. In the third category, where participants consider charting a game of skill they concentrate on outwitting imagined others, shown at work in the market through price movements, and in the fourth, those who consider charting a voyage are constantly working to improve their methods, in a journey towards ever better means of predicting the market. These four categories are linked by the common theme of using charting as a means of 'seeing' the market.

\section{Summary of literature}

The literature discussed above presents several important questions. It is clear that charting is popular, and models explain why this may be so, but it is not clear that it is capable of generating above market returns on investment. It is not clear how chartists actually make investment decisions in the wild, nor whether individuals using charting techniques beat the market. Finance researchers construct ever more rigorous versions of textbook models (e.g. Lo et al 2000), but the assumptions that underpin such models do not necessarily represent the day to day activities of chartists accurately. This study supplies much-needed evidence on the behaviour of chartists. It will build on Mayall's initial contribution to derive a robust conceptualisation of charting behaviour based on how investors make sense of the market (their market ontology), and whether they are 
autonomous in their construction and use of charting tools. A four-way taxonomy of different types of charting style, and four propositions for future research are presented.

\section{Research Method}

Data were obtained from multiple sources and were mainly qualitative. A face-to-face questionnaire was administered at four UK events aimed at non-professional investors in 2005 and 2006. This provided a broad overview of the extent of charting and a screening mechanism for identification of potential interviewees. The main sources of data analysed were interviews with 19 non-professional investors, of whom, 12 had an interest in charting (see Table I). The majority of interviewees were identified from respondents to the questionnaire. Other sources were employed to introduce greater potential difference between interviewees and to reduce bias. Two interviewees resulted from an advertisement on an investment bulletin board and two interviewees were identified through recommendations from other interviewees. An advertisement on the website of smaller company market Ofex yielded no replies and corporate finance issuers were unable to assist in the research. Two interviews, which took place at evening seminars, were shorter and were not recorded. Some of the interviewees were interviewed twice to investigate emerging topics in further detail. In terms of the interviews with chartists, 18 were conducted with the 12 investors interested in charting; interviews lasted between 25 and 50 minutes. Table I summarises the source of each interviewee, the number of interviews and basic characteristics. Due to the geographical dispersion of interviewees, 
two interviews were conducted face to face and the remainder were conducted by telephone.

Insert table I about here

The investor events provided good opportunities for observing the behaviour of nonprofessional investors and the range of products and services available to them. Observations from these events were recorded using field notes, and relevant brochures and demonstration material were collected. Thus, data included interview transcripts, field notes, responses to the survey questionnaire and marketing materials for investor products.

Questionnaire data helped to shape interview outlines and highlight areas of interest. Questionnaires were important in first drawing attention to the prevalence of charting, as $59 \%$ of respondents cited charting as one of their key decision making techniques ${ }^{1}$. Initial interviews were open to allow themes to emerge (Glaser and Strauss, 1968); (Locke, 2001) and then the second round of interviews followed a semi-structured 
schedule. The process of collecting interviewees and conducting interviews continued until saturation was achieved. Analysis was inductive and followed Miles and Huberman's (1994) thematically clustered matrices to identify common elements within the data; questionnaire data, observations of the investor events, and in some instances brochures and literature, offered triangulation points (Webb, Campbell et al., 1965) and additional detail. An ethnomethodological approach to data collection and analysis (Garfinkel and Sachs, 1970) treats interviewees' accounts of their practices and beliefs as meaningful phenomena in their own right (Lynch, 1993), as is appropriate for an empirical project in a relatively unresearched area.

We recognise some limitations in the data. The majority of interviewees were recruited at investor fairs and this could lead us to overemphasise the importance of these events for investors. The interviewees are not a representative sample and we do not claim that the findings are representative of the universe of investors as a whole, although we note that the data displays a number of parallels with that gathered in Australia by Mayall (2006). In the light of these limitations we do not generalise the findings but suggest a number of propositions that can be tested by future research projects.

\section{Initial data analysis}

Among the chartists there was a distinction between those who used charting as the mainstay of their investment decision-making and those who used it alongside other 
methods. The analysis considers all those who used charting to some extent and made investment decisions based on the results and interpretation of charting. However, three interviewees (George, Mike and Nigel) explicitly rejected the title 'chartist.' They made use of the charts in a less systematic way and can be classified as 'incidental chartists.' They are characterised by the use of basic charting tools and the language and concepts of charting, alongside other methods. For example, George visits companies and meets the management personally before investing relatively large sums in illiquid small cap companies. He does, however, make use of charts before buying a stock, using the programme to check the timing of his investment in order to avoid trends that he expects to persist:

If there's something that looks as if it's in a fairly nasty downtrend then I wouldn't want to buy it until there is some indications that downtrend is finished. (George)

Table I highlights that 'incidental chartists' George and Nigel were in the largest portfolio bracket (over $£ 200 \mathrm{k}$ ), and that all the other interviewees investing more than $£ 200,000$ were non-chartists. While it is tempting to regard this fact as significant, there is little to suggest that this is the case. Absolute portfolio size need not bear any relationship to investment success; in the case of George, for example, it reflects career success as an entrepreneur, while Mike, whose portfolio falls in the $£ 150 \mathrm{k}$ to $£ 199 \mathrm{k}$ bracket, professed a poor track record as an investor. Moreover, those with larger portfolios are likely to be older investors who have had time to accumulate substantial assets (Anne, Stewart and Tony) ${ }^{2}$; interviews showed that these investors learned more 'traditional' investment methods many years previously. Interviews also indicated that 
charting has a close linkage with leveraged products such as spread-betting and CFDs, which require smaller portfolios, and therefore attract younger or less capital-rich investors. There is also the possibility that chartists utilise a smaller proportion of their funds in an activity perceived as more risky. With the exception of Max, and Simon (who uses charting for spread-betting trades that require less capital for the risk accepted), the interviewees all had committed the majority of their liquid (non-property, non pension) assets to their share-trading activity.

\section{Developing a taxonomy of charting styles}

Analysis revealed some evidence of each of Mayall's four ideal types of trading among our interviewees: i.e. as a 'scientific' system; as an art based on judgement and intuition; as a game of skill; and as a voyage of exploration. However, the first two types were of particular importance and we found elements of the third and fourth styles distributed among chartists in both the first and second categories. In a scientific system, chartists will strive to remove all elements of human judgement and emotion, seen as a weakness, from their trading. Those who consider charting an art, aim to increase their intuitive, often visual, understanding of the market's movements as a means of divining price movements. We consider that the categories of system and art are important for understanding the activities of chartists, but that they require deepening and strengthening. In our scheme, system encompasses those chartists who use a system based on the interpretative skills of others; these individuals are characterised by their purchase and implementation of whole charting methodologies, from the very simple to 
extremely complex, where their own activity is limited to the carrying out of the processes required by these methodologies. The second category, art, designates those for whom their own interpretative input is of primary importance in the charting process, developing their own methods in the process.

Our analysis identified a further distinction between the charting styles of interviewees, related to the individuals' understanding of stock market ontology - how the market $i s$. While some interviewees believed that the market is chaotic and disordered, others held that while superficially chaotic, the market is organised along certain predictable principles, often related to patterns or cycles of numbers. This distinction in ontology necessarily influences calculative techniques. The first group believe only in the persistence of trends (share price momentum), and are termed here 'trend-seekers'. These trend seekers hunt for stocks where the price is moving steadily in a particular direction, or 'trending', and buy or sell short accordingly. The trend, identified in a variety of ways, is followed until it runs out of momentum. Trend-seekers make no assumption about the underlying nature of the market, beyond the observation that trends tend to have some persistence. As Simon, one trend seeker, said: 'There's no way you can predict share prices, so all I try to do is latch on to price movements'.

The second group are termed 'Pattern seekers'. These pattern seekers believe that it is possible to predict share price movements and changes in price direction. Number series, such as Fibonacci, are used to describe shapes which can be searched for in the market either visually or using an automated system. The pattern will determine not only the 
change in price direction but also the amount that it can be expected to run in that direction. This method involves the ontological assumption that there is some order hidden behind the chaotic appearance of the market, and that these series of numbers have some kind of determining power over the actions of market actors. This belief, clearly articulated by interviewees, links market movement to numbers found in tides, waves, pine cones, and the human body. For example:

Fibonacci ratios exist everywhere, they exist in art, they exist in the human body. If you measure the distance from your shoulder to your ankles, and then you measure the distance of your arm you'll see that that is a Fibonacci ratio, I think it's about 1.618 , or .618 , or your arm is a ratio of your body. When something looks aesthetically pleasing to us, very often we will find that Fibonacci ratios are existing in the relationships between objects in a painting, let's say. (Terry)

Other interviewees used systems based on Elliott Waves and the more complex Delta wave model. In these cases share prices are governed by 'impulse' and 'retracement' waves in groups of five and two, often broken down into substructures. Interviewees also employed 'pivot levels', described by Chris as 'calculators for the day ahead based on the high, low and close of the day before.' Our interviewees' descriptions of these patterns tally closely with those offered by Batchelor and Raymar (2006), summarising textbook charting methods. However, the striking difference here is the unpredictability of the eventual decision making process, which is driven by individual chartist's own interpretative activity and methodological bricolage. 
Further analysis indicated that the distinction between trend-seeking and pattern-seeking could be combined with the system/art distinction to give a four-way taxonomy of charting behaviour, which is presented in Figure 1. Vertically, figure 1 distinguishes between charting styles based on art (interpretative) and systems (non-interpretative). Horizontally, charting styles are separated into trend seeking and pattern seeking. This provides the basis for a taxonomy that identifies four distinct types of charting style. Each of the interviewed chartists was empirically mapped onto the resulting taxonomy. There were no overlapping or missing categories.

Insert Figure 1 about here

Each type of charting style was given a descriptive identifying name. 'NumberCrunching' chartists follow trends and use their own methods, construct their own indicators or even build their own systems: Simon, Robert and Tony. 'Black-Boxing' chartists follow trends but prefer someone else do the interpretative work: Albert, James, and the 'incidental' chartists, Mike, Nigel and George. Chris, Mickey and Terry are the 'Wave-Surfing' chartists, searching for patterns using automated systems and making use of purchased methodologies. Finally, 'Chart-Seeing' investors search for patterns through 
creative visualisation and searching by eye; while envious stories of these individuals are common, only one of our interviewees (Max) fitted this category. The following section considers each type in more detail.

\section{1. 'Black-Boxing'}

'Black-Boxing' makes use of an entirely systematized method that requires little or no interpretative activity. Chartists in this group do not commit significant resources to developing their skills as chartists, and instead rely on simple analysis provided by others. The interpretative system need not be based on the investor's computer; two of the interviewees, Albert and James, subscribe to a newsletter which provides identified trends. Albert, who said he was a 'busy family man' stated that the simplicity and convenience of this approach means that it is the best method he has found in 15 years of investing. All the same, he does not buy without performing his own checks, watching the recommended shares on a simple end of day charting programme. At this point:

'if the graph is going like the north face of the Eiger I may well buy, and I'll hold those until they drop. I only buy shares when they're going up' (Albert)

George, Nigel and Mike all use simple systems in combination with fundamental analysis. George uses the same programme as Albert. Nigel makes use of one particular indicator, the RSI, before making a purchase, although he has only a rough idea of what this indicator does, while Mike, who tends to invest in smaller companies on the basis of 
share tips, also makes a casual reference to the charts before placing his order. Mike stated that if he spots a trend forming - when a share suddenly starts to 'tip up' - he will invest.

Accessibility and ease of use is taken to an extreme by 'black box' programs which automatically process data through a pre-programmed algorithm and generate investment recommendations, which can be transmitted directly to a broker. However, although this kind of software was seen on sale, and interviewees remarked that it existed, none of the interview or survey respondents used this kind of software. It may be suggested that even among the Black-Boxing chartists, those who are prepared to place their investment decisions entirely in the hands of an automated system are relatively rare.

\section{2. 'Number-Crunching'}

Trend-seeking chartists who take decisions into their own hands by constructing their own systems and methods provided much richer and more involved descriptions than their peers in the first category . Number-Crunching uses a barrage of devices for spotting trends; collectively termed 'indicators', these range from the simple moving average, to the recherché Ichimoku (a Japanese technique that draws a cloud beneath or above a stock chart, and from which the user can deduce the existence of a trend). Simon described his initial method as follows: 
The first thing that I actually looked at was a breakout system...you'd buy a stock when it went through the 20 day moving average and keep moving the stop[loss] up, and sell it when it went through the 50 day moving average, and the idea is to capture the sort of wave movement... (Simon)

While this method proved unsatisfactory because small-scale fluctuations in stock prices kept triggering the stop-loss, it served as a basis for Simon to start developing more complex methods. Building new and testing techniques, usually through a bricolage of existing methods, is a crucial part of this group's charting activity.

A particularly important tool for this process is 'back-testing'. This process involves the chartist running a retrospective simulation with historical price data to ascertain whether a particular combination of indicators would have identified a sufficient number of trends. The process is usually computerised and back-testing functionality is an important part of more complex charting software. Robert, discussing his most recent experiment, gave an example of this process:

I can look for shares on the weekly chart where the 14 day RSI is crossing over 50 and the slope of the 40 week exponential moving average is greater than a certain value, and the slope of the 10-week moving average is greater than another value, or certain other conditions, and so on... I can make it [the software package] automatically put little buy and sell signals on the charts, then I can go and look at those charts and say to myself would those have been good buy or sell signals, and if they're not quite right I can adjust them slightly... (Robert) 
This process of testing and adjustment is repeated until a retrospectively successful strategy is discovered, at which point it will be applied in real time. The intention of back-testing is to give the user confidence that a particular method will lead to the discovery of successful trends by the demonstration that it would have done so in the past. The back-testing process is often operated alongside a dummy portfolio, where new methods are tested on a real-time basis, either without risking any money or by using very small stakes. Tony and Simon both use this method, with Simon operating a homemade trading simulator constructed from an Excel spreadsheet and downloaded end of day data.

These systems need not deliver a successful result in every instance. Chartists will accept surprisingly low probabilities of success in their simulations; Robert, for example, is aiming at a success rate of just over $50 \%$. This is acceptable because of the integral role that the stop loss (an order placed at the brokerage to automatically exit a position should the share price move by a certain amount against the trade) plays in the strategies of these chartists.

Chartists view the stop loss as a means of increasing the probability of success across their trades; by setting the stop loss relatively tightly they improve their probability of success. Against this, many chartists argue that stop-losses can be automatically triggered by minor moves in the market causing positions to be exited at a loss when, had they been held longer, they would have resulted in a profit. Simon encountered this in his early methods and confessed that it had presented a serious problem. He ascribes the phenomenon to market volatility. Other interviewees (Tony, Chris, and Mickey) argued 
that stop losses are manipulated by those professional players with the power to move prices, who force the market down in order to trigger automatic sales and buy up stock cheaply. References to an imagined and malevolent other are reminiscent of the 'spoofer' identified by Zaloom (2003), and also recall Mayall's category of charting as a combat or game. Anecdotal evidence indicates that the practice of searching out and triggering stop losses does indeed take place ${ }^{3}$

The stop loss is therefore a crucially important device for chartists, a fact which has not been fully recognised in the finance literature. Park and Irwin (2004) discuss two early studies based on a stop-loss filter role, which showed the method to substantially outperform a buy-and-hold strategy, but there appears to be no work combining stoplosses with more complex charting strategies. Number-Crunching strategies highlight just how difficult an endeavour this testing might be. As Batchelor and Raymar (2006) note, the individual strategies of chartists are vague, complex, and badly documented, but it is precisely this variety of indicator bricolage, overlain with a layer of personal, often unrecognised, interpretative activity on the part of the user, that appears to give NumberCrunching its distinctive character.

In summary, the Number-Crunching chartists make creative use of their resources to try and develop ever more accurate means of spotting price trends in the market. In this category, and indeed in the case of Black-Boxing, the charts are heuristic devices, providing a way of seeing the market (Mayall, 2006) and of managing market dynamics. 
The charts provide a means of searching through an inaccessibly large universe of stocks, so that a final, often visual interpretation can be made. As Tony said:

The charts will tell me what I need to know, and if it looks interesting, either because it's going up or going down, whether it's worth investigating further. (Tony)

In Number-Crunching and Black-Boxing calculative strategies charts are therefore devices for managing market chaos, seeking out and visualising investment opportunities, and reinforcing the calculative skills of their users. For the following two strategies they are tools for revealing the hidden order in markets. The problem is once again that of search, and again there are two clearly identifiable strategies: automation, and a visual, art-based method.

\section{3. 'Wave-Surfing'}

Wave-Surfing uses automated methods involving proprietary methods and systems to search for specific patterns of price movements. In this category are Chris, Mickey and Terry. Once patterns have been discovered, the deterministic nature of number series makes the investment decision relatively easy. Having identified a share that is demonstrating a Fibonacci zigzag, the chartist can determine not only the correct moment to invest, but the distance that will be travelled in a given direction. They can then use the stop loss to quantify potential risk and arrive at a precise risk/reward measure on which to base the decision to trade. 
Wave-Surfing methods are more complex than those of Black-Boxing - the other systembased category - and are predicated on the existence of patterns in the market. So 'system' here takes on a wider definition to include not just the computer software but also the theory and associated technique, which together form an integrated discursive scheme, purchased in its entirety. Terry's story exemplifies the dedication and strong beliefs of the Wave-Surfing chartists. Terry is convinced that there is a code to be cracked in the markets and has dedicated considerable expense, both in financial and personal terms, to learn charting skills. He has spent several thousand pounds on purchasing training CDs and charting software and attending courses. At the time of interview he had spent all his spare time for nine months working on it and intended going full-time after another four months. Terry's method was to attend a course or purchase a training programme, and make use of the method suggested until he decided that it was not accurate enough, or that it failed in some other way, and then repeat the process with a more complex method. He had worked through Elliott waves, found to be too inexact for short-term trading; then a method which integrated Elliott and Fibonacci; then Delta. He believed Delta to be inaccurate in the short term, although he believes that the market does obey the Delta cycles in the longer term, so he moved to a system of Fibonacci laid over Delta; and finally a method integrating other technical indicators with Delta and Elliott which he thinks is capable of giving accurate short term predictions of market movements.

The Wave-Surfing process of investment search is simplified and automated by using software programmes, often sold in conjunction with training materials or at expert seminars hosted by the software manufacturer. These require substantial computing 
power, usually two PCs and two or more screens. When interviewed, Terry was using a software programme developed by the presenter of the course that he had most recently attended. The programme is able, he said, to search for 9,000 combinations of Elliott wave structures. From a list of 300 shares, scanned overnight, it usually produces four or five potential trades to be assessed for risk and return. Mickey also uses a charting package to search for Fibonacci calculations, from which he establishes points of support and resistance for market turns. In practical terms, he says:

it's dead easy ... I select Fibonacci, and I click once on a high point with my mouse and click once on the low point and the lines are automatically drawn. (Mickey)

Chris uses two PCs, each with two screens running two separate charting programmes. He scans the market automatically every minute looking for stocks that are approaching the bounds of trade calculated by his Pivot formula. On spotting a suitable candidate he checks for any outstanding bids or offers, and on being satisfied that the buying or selling that has caused this movement has run out, he will take a position.

\section{Chart-Seeing}

All three of the 'Wave- Surfers' talked about others who had managed to elevate these complex procedures into an intuitive act and who made their judgements by eye. We term this calculative strategy Chart-Seeing. Terry and Mickey seemed envious of this ability, 
referred to as 'intuition' or a 'native skill'. They provided examples of investors they admired who had this ability: in the case of Mickey an eminent City analyst who scanned his charts by eye on the train home, or in the case of Terry a famous trader who over the course of 11 years has become 'attuned' to the market and can 'see instantly' where it is heading. Of the chartists interviewed, only Max has attempted to learn or exercise this skill. Like his wave-surfing peers, he began to learn about charting by attending a number of courses, where he was taught Fibonacci-based (Wave-Surfing) methods. He tried these in the market, and became increasingly frustrated as his losers outnumbered his winners. Eventually, he came to the conclusion that no system could suffice in its entirety, realising 'you've actually got to lay on to that [the most systematic of approaches] a feel for what the markets are doing'. Being a relative beginner, with less than a year's trading experience, Max embarked on a rigorous programme of back-testing to develop his method of identifying patterns visually. He has finally reached the point where he scans a universe of 200 stocks, limited by his chosen specialisation in US equities and his choice of broker, first weekly and then daily to look for patterns forming.

Max's 'feel for what the markets are doing' is based on interpretative activity. Interpretation is crucial for Chart-Seeing. Observation conducted as part of our research included a seminar given by the famous trader mentioned by Terry above. This trader suggested that his method was a 'straight-forward modified Delta pattern' but as he explained the method he employed a considerable amount of interpretation as he showed 
his charts, explaining how he had adjusted the model in responding to various situations to make a profit.

\section{Discussion}

Our analysis of charting styles confirms previous research that technical analysis encompasses a variety of methods and techniques. Our classification of these techniques provides an improved understanding of variations in investor decision-making and raises a number of important points that are discussed in this section. This section finally suggests four propositions for testing by future research.

The first point to stress is the clear distinction between the trend-seekers and the patternseekers. This is based on fundamental differences in the investors' ontology of financial markets. Trend-seekers see the market as chaotic and unpredictable, believing only that price trends have some persistence. Pattern-seekers believe that any observed chaos is only superficial and beneath it the market has hidden structures. Our interviews highlighted a clear distinction; chartists identified strongly with either pattern seeking or trend seeking and firmly believed themselves to be right and the other position wrong. This distinction serves to clarify two assumptions that have appeared in the literature. The first of these is the elision of charting with momentum investing, and then of momentum investing with the search for patterns in the market (Buenza and Stark 2004:375). We show that not all chartists are momentum investors, and that those who are, the trendseekers, do not search for patterns. Park and Irwin's (2004) claim that all charting focuses 
on the search for trends is equally mistaken. The second common misconception is that all necessarily believe in an overarching, transcendent order in the market (Mayall 2006:124). This research clearly shows that this applies only to a section of the charting community.

This distinction perhaps helps us in responding to Menkhoff's (1997) challenge to justify charting as a rational occupation. Some arguments can be advanced for the rationality of trend-seeking. Charts may serve as a rational search method for a momentum strategy; the usefulness of momentum investing has been demonstrated in the US (Jegadeesh and Titman, 2001), although UK evidence is less clear (Liu, Strong et al., 1999; Tonks and Hon, 2003). It is also rational to act in a particular way in the expectation that others will do the same. Models of herding (Banerjee, 1992; Bikhshandani and Sharma, 2001; Hirshleifer and Teoh, 2003) and of asset price bubbles (De Long, Shleifer et al., 1990) demonstrate this. Jegadeesh (2000) suggests that charting methods are used in conjunction with other investment selection methods, paralleling the activities of the incidental chartists, although this was clearly not the case with the other chartists studied.

It is more difficult to make a case for rationality among the pattern seekers. The arguments above hinge on the assumption that certain charting styles may have some value as investment methods, and the same can be said here only in a limited way. While some numbers do have support and resistance effects (Donaldson and Kim, 1993), offering some justification for methods based on important numbers, more sophisticated pattern systems can claim no such evidence. Batchelor and Raymar's (2006) 
demonstrations of the absence of Fibonacci support levels is particularly problematic, while Malkiel (1996) and Jegadeesh (2000) are both insistent that there is no reason for patterns to form in stock prices.

Psychological biases may also help to account for the popularity of charting. It can be argued that systematic overconfidence (Barber and Odean, 2001; Daniel, Hirshleifer et al., 2001) may explain the confidence that individuals show in their own methods and their willingness to invest on the basis of these, even in the face of poor investment performance. The charts themselves, as a psychologically available means of presenting decisions in a visual format (Kahneman and Tversky, 1974), may add to the appeal of the investment technique, the format making decisions easy and accessible. Finally the pursuit of trends has a demonstrated psychological appeal (Andreassen and Kraus, 1998) and this too may contribute to the popularity of charting.

Our analysis suggests that it is mistaken to regard charting as a means for achieving above market returns. Finance research provides scant support for its ability to do so, as do the testimonies of several of the chartists. Yet charting is popular among nonprofessional investors. Menkhoff's challenge can, perhaps, be answered in another way. The research programme of SSF directs attention to the calculative strategies and technologies of individual market agents; Hutchins (1995) shows how sophisticated processes of calculation can be distributed among human actors and technological devices. Buenza and Stark (2004) show this distribution in action in an investment bank's trading room. Charting is amenable to this analysis, as calculation is distributed to 
computer programmes and their designers, to newsletter editors, to fellow chartists, to imagined others such as the 'spoofer', or the malevolent professional traders making fun of stop losses. The charting apparatus in each of the four categories above serve to produce the market, to make it visible for individual investors working alone in their homes, and to allow interaction between them and the market. In each instance, the charting apparatus serves to narrow the range of decisions presented to the individual. Instead of the unfathomable possibilities of the market, possibilities are constrained, and decisions framed and disentangled (Callon, 1998). In this analysis, the importance of charting lies less in its efficacy as an investment selection method, and more in its power to make markets visible and accessible and to simplify and support the huge burden of calculative activity that falls on individual market agents. Charting may, in this sense, be considered rational, as it allows individual non-professional investors to participate as market actors. This is a theme that has been strongly articulated across all four categories: Black-Boxing is quick and efficient; the complex calculative technologies of WaveSurfing allow glimpses of the order behind market chaos; Number-Crunching assembles indicators to pick out the trends which it seeks; and Chart-Seeing presents the individual with available raw materials for visual analysis.

Insert table II here 
We attempted to gauge the extent to which individuals did manage to beat the market, although it is difficult in interviews to gain more than subjective estimates of individual success. The problem is exacerbated by the fact that interviewees tended to compare their returns to their starting point, rather than the market, and that data collection took place during a prolonged bull-market. Where possible, interviewees' returns on investment were ascertained and classified as high (above market), medium (in line with market) and low (below market). This is shown in Table II.

When considering charting purely as a means of gaining above-market returns, our initial discussion provided more support for the rationality of trend-seekers than pattern-seekers and therefore trend-seekers might be expected to show higher returns than patternseekers. However, we failed to find evidence to support this expectation; some patternseekers were very successful, and some trend-seekers were not. Additionally, our analysis indicated that art-based charting styles have a higher status than system-based ones, and therefore it might be expected that art-based charting styles would be associated with higher returns. Again, there was no evidence to support this. Overall, there was no evidence to indicate that there was an association between charting style and returns on investment; instead our analysis suggested that returns may be associated with the interpretative skills and activities of the individual chartist. Therefore, our first proposition is as follows:

P1: There is no association between charting style and the financial return on investments 
The lack of association between charting style and financial return appears to underscore the central claim of this article - that, while the charts form part of the toolkit of heuristic devices that the individual investors uses to manage and control the market, individual investment performance is largely dependent on the tacit skills of the chartist. The clearest example of this was given in a seminar we attended, where a chart-seeing professional trader set out a theory of markets based on a four day cycle, illustrated by charts. The charts frequently bore no clear relation to either the cycle's predictions, or the trader's comments, and instead appeared to offer a heuristic support for the trader's own tacit interpretative skills, developed over a long period of time. In this sense we can perhaps answer Menkhoff's challenge: it is entirely rational for an individual to use tools that support her activities, where the tools serve productively to support calculative activity but not determine the eventual investment decision. In this instance we can see that there may be a distinction between the 'art' and 'science' categories of chartist, but the argument can equally be made that calculation is distributed (Hutchins, 1995) to the compilers of newsletters or charting software, who themselves rely on charts as heuristic devices.

There are parallels here with discussion of valuation models used by professional securities analysts. Barker (1999) and Demirakos (2004) show that analysts consistently prefer simple models such as price to earnings ratio and dividend yield to sophisticated models of discounted cash-flow and residual income, the latter considered to be too complicated for real life situations. Barker identifies a need for further research in understanding why simple models are preferred; the implication of chartists' experience is that the analysts' tacit expertise is of primary importance when grappling with the 
complexities of real life company valuation, and the simpler ratios form a more useful, flexible and available heuristic device in dealing with this process.

Our analysis also highlighted the importance of the stop-loss in the investment strategies of chartists. The stop-loss limits the potential downside of trades, but may also lead to closing a trade too early and crystallizing a loss rather than achieving an eventual profit. Further research is required to establish the effect of stop-losses on the profitability of investment strategies. Hence our second proposition:

P2: There is a positive association between the use of stop-losses and investment returns

As with $P 1$, this proposition has another implication for future research. We suggest that the stop-loss often performs a markedly differing function for individual chartists than is supposed in finance literature. Rather than being simply another part of the chartist's tool kit, it appears that the utility of the stop-loss is closely related to the significance of the charts as heuristic devices for investors. The stop-loss forms an action-based ruling on the validity of any given trading set up, informing the chartist at an early stage whether he is 'right' in his combination of rules and indicators. Terry alludes to this with the comment that the stop loss resembles a 'slap on the wrist' that will 'invalidate your analysis'. In this sense the power of the stop loss lies in its ability as a corrective device for illconceived conceptual arrangements on the part of the individual, not only improving investment returns but also continuously enhancing the chartist's heuristic apparatus and potentially improving her investment performance. This aspect of the stop-loss is, unfortunately, less amenable to testing than its relationship to profitability. 
Our analysis also indicated that there was relatively little movement between charting styles. This is particularly surprising in the case of the art/system divide. As art has a higher status than system, it might be expected that there would be a progression from system to art. This was certainly the case with Max, who moved to a visual style of pattern spotting after an unsuccessful attempt at a system-based approach. Apart from this there is little mobility among our interviewees and it appears that the choice between system and art-based charting styles is associated with personal circumstances and preference. System-based styles are chosen for reasons of convenience and practicality; its methods save time and offer the user an efficient means of sifting through large volumes of data. Art-based styles are popular with those who enjoy experimentation and are prepared to devote time and effort to discovering new methods; Max has, by means of a personal windfall, been given a period of time where he could devote extensive effort to perfecting his charting style. There is less conceptual support for movement between trend-seekers and pattern-seekers as this would require a shift in market ontology, a change in the individual's understanding of how markets function. However, Chris moved from 'Number-Cruncher' to 'Wave-Surfer', making an ontological leap as he became convinced of the usefulness of number series and other predictive indicators. This raises some interesting issues for further investigation. Our third proposition, then, is:

P3: Individuals' charting styles are relatively static and are determined by exogenous (non-market) factors 
There are again parallels with the methods used by professional securities analysts, where choice of methodology appears to be influenced by the industry sector, type of firm, and expectations of the market (Barker, 1999; Block, 1999; Demirakos, Strong et al., 2004). It may be the case here too that the evidence of chartists can illuminate new avenues of research on professional analysts; perhaps truly exogenous factors such as personal preferences and skills, as well as the circumstances and customs of employment, may be shown to influence valuation methodologies.

Propositions one to three underscore the central argument of this study - that the use of charting is not solely associated with generating investment returns. We have suggested that its power as a heuristic device, enabling individuals to organize, manage and understand the complexities of the market is equally, if not more important to users. We noted during interviews that the charts provided a frame of reference for seeing, recalling and talking about the market; interviewees would often refer to a chart as they illustrated a point or substantiated a claim. We also note that charting offers individuals other nonmarket returns. The experimentation of the Number-Crunching investors provided them with enjoyment, pride, and a sense of mastery over the market. Across all categories mastery of techniques provided investors with prestige. In summary, returns from charting are much broader than a simple return on investment. Hence, we suggest a final proposition for future investigation:

P4: Investors use charting for its heuristic power rather than its ability to generate financial returns. 


\section{Conclusion}

In this article we have conducted an analysis of charting styles, and classified them into four groups depending on whether they were art or system based and whether they were seeking trends or patterns. The visualisation of a financial market is inexorably linked to, if not driven by, chartists' views on market ontology and efficiency. Our taxonomy has shown how differences in seeing the market, driven by fundamental differences in chartists' conception of what the market is, relate to varied calculative strategies. An investor who believes that markets are efficient has little need of this kind of graphic visualisation, and will simply buy a tracking fund. The purpose of charting is exactly the opposite; it provides investors with visual illustrations of the structure of markets, showing amongst market chaos the gold threads that offer the chartist opportunities for profit. A chartist, almost by definition, may not believe in efficient markets, whatever the evidence to the contrary; chartists who were less successful blamed themselves for deviation from their methods, and looked forward to making 'big money one day' (Chris). We did not interview, meet, or hear of, anyone who was an ex-chartist.

Two major interlinked themes underpin the findings in this study. These themes are extremely important because they affect the validity of assumptions of some earlier research. The first is that the use of charting and the choice of charting style do not 
appear to be associated with financial returns. The second is the importance of interpretative and tacit skills in the activities of chartists. We have shown no clear relationship between charting style and individual investors' returns and have suggested that returns may be dependent on individuals' own interpretative skills. This presents problems for researchers attempting to determine the usefulness of charting, or its popularity with investors, on the basis of textbook methods. While the similarity between our interviewees' accounts and textbook presentations of charting method shows that these are accepted as a basis for individual charting methods, it is clear that the strategies pursued by individuals may in fact be very different from those methods. We therefore suggest that attention could usefully be given to the way in which individuals develop their own interpretative strategies, and that it would be beneficial for some future research to focus on individual rather than generic charting strategies.

There may also be implications for practitioners such as investors, company managers and market supervisors. In particular, practitioners should be aware of the popularity of charting as an investment method. Rather than dismissing it as irrational or speculative, it may help practitioners to understand that it is employed by relatively sophisticated investors, and appreciate that it may have its roots in attempts to manage and make sense of the market in a rational manner. 
Finally, we suggest that previous studies that aim to demonstrate or refute the efficacy of charting methods have only limited scope for developing our understanding of the popularity of charting among investors. This study has shown that the appeal of charting lies in the way that it allows investors to make sense of, manage, and participate in the markets. As an integrated discursive scheme, supplying a way of understanding financial markets and the tools to turn this understanding into investment practice, charting can be considered a performative technique in the sense of Callon $(1998,2007)$. This aspect of the appeal of charting is one which may be most fruitfully investigated by future research.

\section{References}

Abolafia, M. (1998). Markets as cultures: an ethnographic approach. The Laws of Markets. M. Callon. Oxford, Oxford University Press: 69-85.

Allee, K. D., Battacharya, N., et al. (2007). "Proforma disclosure and investor sophistication: external validation of experimental evidence using archival data." Accounting Organizations and Society 32(3): 201-222.

Andreassen, P. and Kraus, S. (1998). Judgemental prediction by Extrapolation. Harvard, Mimeo.

Baker, W. (1984). "The Social Structure of a National Securities Market." American Journal of Sociology 89(4): 775-811. 
Banerjee, A. (1992). "A Simple Model of Herd Behaviour." Quarterly Journal of Economics 107(3): 797-817.

Barber, B. and Odean, T. (2000). "Trading is Hazardous to your Wealth: the common stock performance of individual investors." Journal of Finance 55(2): 773-799.

Barber, B. and Odean, T. (2001). "Boys will be boys: gender, overconfidence and common stock investment." Quarterly Journal of Economics(February): 261-292.

Barber, B. M. and Odean, T. (2004). All that Glitters: The Effect of Attention and News on The Buying Behaviour of Individual and Institutional Investors, University of California.

Barker, R. G. (1999). "Survey and Market-based Evidence of Industry-dependence in Analysts' Preferences Between the Dividend Yield and Price-earnings Ratio Valuation Models." Journal of Business Finance \& Accounting 26(3-4): 393-418.

Batchelor, R. and Ramyar, R. (2006). Magic numbers in the Dow. London, Cass Business School.

Bikhshandani, S. and Sharma, S. (2001). "Herd Behaviour in Financial Markets." IMF

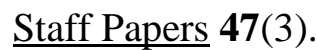

Block, S. B. (1999). "A Study of Financial Analysts: Practice and Theory." Financial Analysts Journal 55(4): 86.

Bloomfield, R., Libby, R., et al. (1999). "Confidence and the welfare of less-informed investors." Accounting Organizations and Society 24(8).

Buenza, D. and Stark, D. (2004). "Tools of the trade: the socio-technology of arbitrage in a Wall Street trading room." Industrial and Corporate Change 13(2): 369-400. 
Callon, M. (1998). The embeddedness of economic markets in economics. The Laws of Markets. M. Callon. Oxford, Oxford University Press: 1-58.

Callon, M. (2007). What does it mean to say that economics is performative? Performing Economics. D. MacKenzie, F. Muniesa and L. Siu, Princeton University Press.

Callon, M. and Muniesa, F. (2003). "Les marchés économiques commes dispositifs collectifs de calcul." Réseaux 21(122): 189-233.

Daniel, K., Hirshleifer, D., et al. (2001). "Investor psychology in capital markets: evidence and policy implications." Journal of Monetary Economics 49: 139-209.

De Bondt, W. (1998). "A Portrait of the Individual Investor." European Economic Review 42: 831-844.

De Long, J., Shleifer, A., et al. (1990). "Positive Feedback Investment Strategies and Destabilising Rational Speculation." Journal of Finance 45(2): 379-395.

Demirakos, E. G., Strong, N. C., et al. (2004). "What Valuation Models Do Analysts Use?" Accounting Horizons 18(4): 221.

Donaldson, R. and Kim, H. (1993). "Price Barriers in the Dow Jones Industrial Average." Journal of Financial and Quantitative Analysis 28(3): 313-330.

Fama, E. (1970). "Efficient capital markets: a review of theory and empirical work." Journal of Finance 25: 383-417.

Fama, E. (1991). "Efficient Capital Markets II." Journal of Finance 46(5): 1575-1617.

Frederickson, J. R. and Miller, J. S. (2004). "The effects of proforma earnings disclosures on analysts' and non-professional investors' equity valuation judgements." The Accounting Review 79(3): 667-686. 
Garfinkel, H. and Sachs, H. (1970). On the Formal Structure of Practical Actions. Theoretical Sociology. J. McKinney and E. Tiryakian. New York, Appleton Century Crofts: 337-366.

Glaser, B. and Strauss, A. (1968). The Discovery of Grounded Theory: Strategies for Qualitative Research. London, Weidenfeld and Nicholson.

Godechot, O. (2001). Les Traders. Paris, la Découverte.

Hirshleifer, D. and Teoh, S. (2003). "Herd behaviour and cascading in capital markets: a review and synthesis." European Financial Management 9(1): 25-66.

Hutchins, E. (1995). Cognition in the Wild. Cambridge, Mass., The MIT Press.

Jegadeesh, N. (2000). "Foundations of Technical Analysis: Computational Algorithms, Statistical Inference, and Empirical Implementation: Discussion." Journal of Finance 60(4).

Jegadeesh, N. and Titman, S. (2001). "Profitability of Momentum Strategies." Journal of Finance 56: 699-720.

Kahneman, A. and Tversky, D. (1974). "Judgement under uncertainty." Science 185: 1124-1131.

Knorr Cetina, K. (2005). From pipes to scopes: the flow architecture of financial markets. The Technological Economy. A. Barry and D. Slater. Abingdon, Routledge: 122141.

Knorr Cetina, K. and Bruegger, U. (2000). "The Market as an Object of Attachment: Exploring Postsocial Relations in Financial Markets." Canadian Journal of Sociology 25(2): 141-168. 
Knorr Cetina, K. and Bruegger, U. (2002). "Global Microstructures: The Virtual Societies of Financial Markets." American Journal of Sociology 107(4): 905-950. Lewis, M. (1989). Liar's Poker. London, Coronet.

Liu, Strong, et al. (1999). "UK Momentum Test." Journal of Business Finance and Accounting 26: 249-268.

Lo, A. W., Mamaysky, H., et al. (2000). "Foundations of Technical Analysis: Computational Algorithms, Statistical Inference, and Empirical Implementation." The Journal of Finance 55(4): 1705-1765.

Locke, K. (2001). Grounded Theory in Management Research. London, Sage Publications.

Lynch, M. (1993). Scientific practice and ordinary action. Cambridge, Cambridge University Press.

MacKenzie, D. (2003). "An Equation and its Worlds." Social Studies of Science 33(6): $831-868$

MacKenzie, D. (2003). "Long Term Capital Management and the Sociology of Arbitrage." Economy and Society 32(3): 349-380.

MacKenzie, D. (2004). "The big bad wolf and the rational market: portfolio insurance, the 1987 crash and the performativity of economics." Economy and Society 33(3): 303-330.

MacKenzie, D. and Millo, Y. (2003). "Constructing a market, performing theory: the historical sociology of a financial derivatives exchange." American Journal of Sociology 109(1): 107-145.

Malkiel, B. G. (1996). A Random Walk down Wall Street. New York, W.W. Norton. 
Malkiel, B. G. (2003). "The Efficient Market Hypothesis and Its Critics." The Journal of Economic Perspectives 17(1): 59-82.

Mayall, M. (2006). "Seeing the Market: Technical Analysis in Trading Styles." Journal for the Theory of Social Behaviour 36(2): 119-140.

Menkhoff, L. (1997). "Examining the Use of Technical Currency Analysis." International Journal of Financial Economics 2: 307-318.

Miles, M. and Huberman, A. (1994). Qualitative Data Analysis. London, Sage Publications.

Odean, T. (1998b). "Are investors reluctant to realize their losses?" Journal of Finance $53(5)$.

Park, C.-H. and Irwin, S. H. (2004). The Profitability of Technical Analysis: A Review. AgMAS Project Research Report, University of Illinois at Urbana-Champaign: 04.

Preda, A. (2007). "The sociological approach to financial markets." Journal of Economic Surveys 21(3): 506-533.

Preda, A. (in press). Where do Analysts Come From? The Case of Financial Chartism. Market Devices. M. Callon, F. Muniesa and Y. Millo. Oxford, Blackwell.

Shliefer, A. and Summers, C. (1990). "The Noise Trader Approach to Finance." Journal of Economic Perspectives 4(2): 19-33.

Taylor, M. and Allen, H. (1992). "The use of technical analysis in the foreign exchange market." Journal of International Money and Finance 11(3): 304-14.

Tonks and Hon (2003). "Momentum in the UK Stock Market." Journal of Multinational Financial Management 13(1): 43-70. 
Webb, E., Campbell, D., et al. (1965). Unobtrusive Measures. Chicago, Rand McNally.

Zaloom, C. (2003). "Ambiguous numbers: Trading technologies and interpretation in financial markets." American Ethnologist 30(2): 258-272.

Zaloom, C. (2006). Out of the Pits. Chicago, University of Chicago Press.

Zuckerman, E. (2004). "Structural incoherence and stock market activity." American Sociological Review 69(405-432).

\begin{abstract}
NOTES
${ }^{1}$ It may be the case that chartists are more likely to be encountered at investor fairs, as these are one of the places where charting methods are sold and promoted. This could be because investors are converted to charting at fairs, or chartists attend out of an existing interest. However, several non-charting interviewees were also recruited at investor fairs (see table I). There is, therefore, insufficient evidence to demonstrate that interviewees recruited at investor fairs are more likely to be predisposed to charting.

${ }^{2}$ Initially, there were no observable patterns with regard to the age of the investors, the size of investment or wealth. There was a distinct lack of women among the non-professional investors and we were only able to obtain one woman interviewee, who was not a chartist.

${ }^{3}$ Donald Mackenzie recalls a professional trader remarking that on a quiet day he and his colleagues would 'bounce the price around' to take out the stop losses.
\end{abstract}

